\title{
A formação territorial de Coronel Fabriciano (sede) e de Ipatinga (distrito) entre as décadas de 1920 e 1960: afinal, quem são os Estabelecidos e os Outsiders? \\ Territory formation in Colonel Fabriciano (county) and Ipatinga (township) between the 1920's and the 1960's; Who are, after all, the Stablished and the Outsiders?
}

\author{
Patrícia Falco Genovez* \\ Vagner Bravos Valadares**
}

\begin{abstract}
Resumo
A emancipação de Ipatinga, ocorrida em 29 de abril de 1964, foi o resultado de um movimento complexo envolvendo o contexto nacional das décadas de 1950 e 1960, a instalação da Usiminas (maior complexo siderúrgico já construído na América Latina) e um imbricado processo de formação territorial que envolveu tanto a sede (Coronel Fabriciano) quanto o próprio distrito (Ipatinga). Nas bases dessa formação ancoraram-se as redes de poder e de sociabilidade que geraram as territorialidades capazes de articular a futura emancipação de Ipatinga. Será, portanto, esse processo de formação que enfocaremos, sem perder de vista sua relação com um outro processo mais amplo de mudança pelo qual esse território passou: de mero distrito até os anos iniciais da década de 1950, transformou-se em um objeto de interesse entre políticos regionais, governo do Estado de Minas Gerais e Governo Federal. Isso se deu após o anúncio da construção da Usiminas entre os anos de 1956 e 1957. Por tratar-se de um período recente e pouco estudado pela historiografia relativa à região do Rio Doce (leste de Minas Gerais), a formação territorial de Coronel Fabriciano e de Ipatinga se configura em um objeto privilegiado não só academicamente, mas de um período da história dessas cidades que ainda não teve um esforço de análise consistente.
\end{abstract}

Palavras-chave: Formação Territorial. Emancipação. Estabelecidos. Outsiders.

\footnotetext{
*Doutora em História pela Universidade Federal Fluminense; professora da Universidade Vale do Rio Doce.E-mail: patricia.genovez@superig.com.br

** Mestre em Gestão Integrada do Território pela Univale; professor das Faculdades Integradas de Caratinga. E-mail: vagnerbvaladares@gmail.com
} 


\begin{abstract}
Coronel Fabriciano and Ipatinga are two cities in the Brazilian Southeastern countryside, near the Doce river, about 400 kilometers west of the Atlantic Ocean costal line. Studies on their historical process of territorial formation allow one to grasp the grounds on which their power and sociability networks are rooted. These social nets originate territorialities able to articulate the understanding of the outgrowth of some villages and municipalities that from both divide and incorporate each other. Dealing with this process demands, as first step, some analysis on Territory and Territorialities concepts, and here these are merged with some of Norbert Elias typologies (The Established and Outsiders - 1965). So, this is the main process studied in this essay, of course, having in mind another deep grounded process that took place all throughout this region, mainly alongside the built up of a steel mill (Usiminas). This issue had very little attention by historical research of this part of the countryside, because the territorial formation of Coronel Fabriciano and Ipatinga is not only an academic issue, but also a deep social subject. As one could imagine that even after almost half a century, some political and social dimensions prevent a deep analysis endeavor.
\end{abstract}

Key-words: Territorial formation. Municipality formation. Established. Outsiders.

\title{
Introdução
}

A historiografia da região do Rio Doce apresenta lacunas consideráveis. Essas lacunas tornam-se ainda mais significativas quando a temática se relaciona aos períodos que antecederam ou sucederam imediatamente o Golpe Militar de 1964. De um modo geral, verifica-se uma espécie de "apagão" na memória histórica, tanto no que respeita à organização documental quanto à disposição de testemunhas em relatar os fatos ocorridos. Assim, vários episódios históricos que envolveram cidades-polos como Governador Valadares, Coronel Fabriciano e Ipatinga foram amnesiados na memória social e transformaram a década de 1960 em um período nebuloso, de difícil acesso aos historiadores. É justamente nesse período que ocorreram eventos de extrema violência que, de forma direta ou indireta, estiveram alinhados com o Golpe Militar. Dentre esses eventos, podemos citar: o choque entre policiais e trabalhadores da Usiminas, ${ }^{1}$ conhecido como o Massacre de

${ }^{1}$ A Usiminas foi fundada sob a proposta mineira de superação da produção da Companhia Siderúrgica Nacional - CSN. Sua construção se deu estrategicamente no Aglomerado Urbano do Vale do Aço (AUVA), o principal polo siderúrgico do Estado de Minas Gerais, no distrito de Ipatinga, apresentando-se quase 
Ipatinga, estreitamente relacionado a sua emancipação; e o empastelamento do jornal 0 Combate, cuja sede, em Governador Valadares, fora destruída por um grupo paramilitar a serviço de latifundiários locais.

Historicamente, a população que viu de perto todos esses eventos não os percebe ou não os admite como algo vivenciado há meio século e ainda prefere silenciar. Aliás, é sintomático que, resguardado certo prazo para acesso aos documentos do período, ainda ocorra um esforço para que esse passado possa imergir. Entretanto, consideramos que, se por um lado ainda é difícil acessar tais memórias, por outro, a complexidade política e social dessa historiografia pode ganhar profundidade se atrelarmos a esse cenário uma dimensão territorial. Acreditamos que a compreensão dos eventos, que de alguma forma estiveram intimamente relacionados ao Golpe Militar nessa região, podem e devem ser apreendidos a partir da formação histórica desse território e das múltiplas territorialidades que estiveram envolvidas no processo.

Desta forma, é possível recuperar algumas nuances deste imbricado caleidoscópio nos quais atores e vontades políticas ganham um território concreto como palco. Mas, vale ressaltar, esse palco/território não é estático e encontra-se imerso em um processo único em que tempo e espaço se retroalimentam em um continuum. Nesse sentido, recortamos o processo histórico de formação territorial de Coronel Fabriciano e de Ipatinga com o objetivo de percebermos as bases nas quais se ancoraram as redes de poder e de sociabilidade que geraram as territorialidades capazes de articular a futura emancipação de Ipatinga. Inicialmente, apresentaremos uma breve discussão sobre Território e Territorialidades, conceitos que utilizaremos em conjunto com as tipologias elisianas Estabelecidos e Outsiders. Posteriormente, trataremos da formação do território de Coronel Fabriciano e de Ipatinga.

\section{Território, Territorialidades, Estabelecidos e Outsiders: uma discussão teórica}

A ideia de território é permeada por contradições e a discussão sobre esse conceito está longe de ter suas tensões resolvidas. Para encontrar uma

finalizada em fins de 1962. Em novembro desse mesmo ano, o alto forno começou a funcionar. Em 1963, todas as principais seções da usina estavam em funcionamento. Em vista dos custos terem se elevado no curso da construção, o BNDES foi forçado a fazer contribuições para ver o projeto concluído com sucesso e, ao fazê-lo, tornou-se acionista majoritário da empresa. Ver EMMENDOERFER, Magnus Luiz. Controle do Tempo: a percepção dos atores gerenciais da Unsiminas S.A. (Dissertação de Mestrado) Curso de Pós Graduação da Universidade Federal de Santa Catarina, Florianópoles, 2004. 
definição, é necessário resolver um problema de natureza epistemológica. Tradicionalmente, o território, em sua concepção mais comum, é entendido como divisão político-geográfica. Essa concepção coloca o Estado como definidor do território. Portanto, envolve diretamente uma questão de poder político e de demandas político-administrativas.

O território no sentido político-administrativo é fundamentalmente o território nacional: espaço que delimita uma ordem jurídica e política, com suas linhas, limites e fronteiras. A historiografia brasileira tradicionalmente utilizou o território como dado e premissa, nos termos em que se encontra no conceito definido por Friedrich Ratzel, ${ }^{2}$ na segunda metade do século XIX. Os estudos mais recentes, influenciados pela História Cultural, não questionaram essa matriz teórica, centrando a análise nos aspectos ligados à representação, à mentalidade e ao simbólico. Milton Santos propôs uma alternativa a essa matriz ratzeliana do conceito. 0 território, para o autor, é o espaço construído pelo trabalho, pela energia e pela informação materializada em formas-conteúdo que revelam relações marcadas pelo poder, reafirmando as noções postas por Raffestin. ${ }^{3}$

Entretanto, o território deve ser apreendido em múltiplas vertentes e diversas funções, podendo sobrepor-se permanente ou temporariamente. Para Coraggio, como ato histórico por excelência, o território ocorre em uma dada relação espaço-temporal, isto é, resulta de processos sociais e das relações dos homens com a natureza, portanto, de relações sócio-espaciais centradas e emanadas do cotidiano dos indivíduos em diferentes centralidades, temporalidades e territorialidades. ${ }^{4}$ Nesse sentido, é criação coletiva, recurso institucional e natureza, constituindo-se território vivido de relações sociais e sócio-ambientais, onde há sentimento de pertencimento - identidades formadas com base em raízes histórico-culturais, histórico-ambientais e histórico-espaciais. ${ }^{5}$

${ }^{2} \mathrm{O}$ alemão Friedrich Ratzel, na segunda metade do século XIX, introduziu a noção de território na Geografia, retirando-a das ciências naturais. A Geografia Clássica, que prevaleceu até os anos 1960, tem o centro de atenção no território associado ao Estado-Nacional. Nesse sentido, reconhece apenas uma única instância territorial e, portanto, uma única categoria de análise. É o poder do Estado-Nacional que define a territorialidade do espaço. Ver MACHADO, Mônica Sampaio. Geografia e Epistemologia: Um Passeio pelos Conceitos de Espaço, Território e Territorialidade. In: http://www2.uerj.br/ dgeo/geouerj1h/monica. htm, em 25 de outubro de 2005 .

${ }^{3}$ Ver RAFFESTIN, Claude. Por uma geografia do poder. São Paulo, Ática, 1993. SANTOS, Milton. Espaço e método. São Paulo: Nobel, 1985; SANTOS, Milton. Natureza do Espaço: Técnica e Tempo. Razão e Emoção. São Paulo: HUCITEC, 1996.

${ }^{4}$ CORAGGIO, J. L. Territórios em transicion y la planificacion regional en América Latina. Quito: Ciudad, 1987.

${ }^{5}$ SANTOS, Milton. \& SILVEIRA, Maria Laura. O Brasil. Território e sociedade no início do século XXI. São Paulo/ 
Na perspectiva complexa de Haesbaert, os territórios se formam de modo heterogêneo e por sobreposição, fundados nas contradições sociais, nas relações de poder e na diversidade cultural. ${ }^{6}$ Assim, o território vai de uma dominação político-econômica mais concreta e funcional à apropriação mais subjetiva e/ou cultural-simbólica e descende de um continuum entre o espaço físico-natural como uma espécie de matéria-prima dos processos de territorialização e dos poderes neles incorporados, através dos sujeitos aí envolvidos. Nessa linha de pensamento, podemos falar em dois grandes "tipos ideais", ou referências, para investigar o território:

um mais funcional, pormenorizado na maior parte das abordagens, e outro, mais simbólico, que vem se impondo em importância nos últimos tempos. Enquanto "tipos ideais" eles nunca se manifestam em estado puro, ou seja, todo território "funcional" tem sempre alguma carga simbólica, por menos expressiva que seja, e todo território "simbólico" tem sempre algum caráter funcional, por mais reduzido que pareça.?

Assim, o autor nos apresenta uma forma de discutirmos o território em uma perspectiva que congrega desde uma visão mais funcionalista até uma visão mais simbólica. Na gradação entre um suporte mais materialista e outro mais cultural, temos o espaço territorial como sinônimo de materialidade, ou seja, é a materialidade do mundo, o espaço como sinônimo de base mais cultural, chamado de território simbólico. É o espaço como referência identitária.

Ainda dentro dessa perspectiva, a territorialidade pode ser usada para conter ou restringir, bem como para excluir, e os indivíduos que exercem controle não precisam estar dentro do território, nem próximos a ele. Em outras palavras, uma cerca ou um muro podem controlar, da mesma forma que um sinal de "não passe". A lógica, portanto, é que a territorialidade estabelece um controle sobre uma área e pode também servir como um meio de controlar pessoas, coisas e relações. ${ }^{8}$

Nessa linha argumentativa, o território é constituído por pelo menos três elementos: malhas, nós e redes. Em graus diversos, em momentos

Rio de Janeiro: Record, 2005; SANTOS, Milton. Metamorfose do espaço habitado. 4. ed. São Paulo: Hucitec, 1996.

${ }^{6}$ HAESBAERT, R. Identidades territoriais. In: CORREA, R. L.; ROSENDAHL, Z. Geografia cultural - manifestações da cultura no espaço. Rio de Janeiro: Ed. da UERG, 1999.

${ }^{7}$ HAESBAERT, Rogério. Território e multiterritorialiadade: um debate. GEOgraphia, Ano IX, n. 17, 2007, p. 23.

${ }^{8}$ SACK, Robert David. Territorialidade Humana: sua teoria e história. Cambridge: University Press, 1986. 
diferentes e em lugares variados, todos são sujeitos sintagmáticos que produzemterritórios.Logo, a territorialidade refletea multidimensionalidade do vivido territorial pelos membros de uma coletividade, conectados em redes. Assim, "os homens vivem, ao mesmo tempo, o processo territorial e o produto territorial por intermédio de um sistema de relações existenciais e/ ou produtivas". ${ }^{9}$ Então, o território, antes de ser uma fronteira, é um conjunto de lugares conectados a uma rede de itinerários, e a territorialização engloba ao mesmo tempo o que é itinerário e o que é mobilidade, ou seja, engloba tanto os itinerários quanto os lugares..$^{10}$ Por essa característica, o território é ao mesmo tempo raiz e cultura. Dessa forma, a territorialidade não pode se reduzir ao estudo de seu sistema territorial, já que ela é a expressão de um comportamento vivido, englobando, simultaneamente, a relação com o território e, a partir dela, a relação com o espaço estrangeiro. ${ }^{11}$ Portanto, toda análise de territorialidade se apoia sobre uma relação interna e outra externa. Ou seja, a territorialidade é uma oscilação contínua entre o fixo e o móvel, entre o território que dá segurança, símbolo de identidade, e o espaço que se abre para a liberdade. 0 peso das relações territoriais recai, dessa forma, também sobre a cultura. ${ }^{12}$

Dentro desse continuum entre o funcional e o simbólico, entre o fluxo e as múltiplas relações de poder, entendemos estas últimas como elementos essenciais e definidores que constroem territórios e os redefinem a todo instante. Se o poder tem como fonte as relações humanas mais variadas, ele também pode assumir diversas formas. Na linguagem eliasiana, isso quer dizer que há grupos ou indivíduos que "podem reter ou monopolizar aquilo que os outros necessitam, como comida, amor, segurança, conhecimento etc. Portanto, quanto maior as necessidades destes últimos, maior é a proporção de poder que detêm os primeiros". ${ }^{13}$ Assim, o poder, na teoria de Elias, não se resume ao que ocorre entre senhores e servos, dominadores e dominados, mas pode ocorrer entre indivíduos de uma mesma família, entre membros de bairros vizinhos, e pode se mostrar também nas mais variadas situações, como a maneira que os indivíduos se portam à mesa, a maneira de se vestir e a aceitação (ou não) de outros indivíduos em atividades cotidianas

${ }^{9}$ RAFFESTIN, Claude. Por uma geografia do poder. São Paulo: Ática, 1993, p. 40-41.

${ }^{10}$ BONNEMAISON, J. Viagem em torno do território. In: CORRÊA, R. L.; ROSENDHAL, Z. (Org.). Geografia cultural: um século. Rio de Janeiro: EDUERJ, 2002. v.3, p. 107.

${ }^{11}$ Ibidem.

${ }^{12}$ Ibidem

${ }^{13}$ ELIAS, Norbert. O processo civilizador. v. 1. Rio de Janeiro: Jorge Zahar, 1994, p. 53. 
de lazer. Dessa maneira, é possível definirmos os mais variados tipos de territórios e verificar a existência das mais diversas formas de exercício de territorialidade.

Mas há outras duas categorias que Elias nos apresenta que podem ser muito interessantes como chave de leitura para a formação histórica do território: Estabelecidos e Outsiders. Em pesquisa realizada durante aproximadamente três anos em uma pequena comunidade industrial urbana, designada como Winston Parva, no sul da Inglaterra do século XX, Elias e Scotson mostram uma clara divisão, em seu interior, entre um grupo de residentes estabelecidos desde longa data em um bairro relativamente antigo e, ao redor dele, duas povoações formadas há menos tempo, cujos moradores eram tratados pelo grupo dos estabelecidos como outsiders. A pesquisa começou, como muitas outras, porque moradores de um desses bairros tinham um índice de delinquência sistematicamente mais elevado que o dos outros. O que Elias e Scotson nos mostram nesse livro é a relação de poder entre dois grupos de moradores que não se diferenciam quanto a seu tipo de ocupação, religião, educação, nacionalidade, classe social, cor, raça, mas, sim, no que se refere ao tempo em que residiam na comunidade. Em outras palavras, embora Elias e Scotson não tenham utilizado os conceitos de território e territorialidade, podemos propor uma aproximação: o caso da pequena comunidade em questão mostra a ocupação de um espaço, a definição do mesmo como um território e o exercício preliminar de uma dada territorialidade por um grupo que, uma vez estabelecido territorialmente, passou a exercer uma estratégia de domínio sobre o que considerava ser seu território, impondo aos grupos que chegaram posteriormente a denominação de outsiders ("os de fora”). Será, portanto, a partir dessa chave de leitura que proporemos uma aproximação ao processo de formação histórica do território de Coronel Fabriciano e Ipatinga.

\section{De Antonio Dias a Ipatinga: a formação de territórios}

No intuito de relacionar o objeto da pesquisa com os conceitos trazidos pela discussão sobre território, o que se propõe inicialmente é estabelecer alguns recortes e critérios importantes para o entendimento da formação de um território. Para tanto, elaboramos uma síntese sobre o seu nascimento, tendo como referencial teórico de destaque o pensamento de Haesbaert e a historiografia pertinente à formação histórica local.

Como já citado anteriormente, Haesbaert, a partir de Raffestin, compartilha a concepção de que território descende de um continuum como 
matéria-prima dos processos de territorialização e dos poderes neles incorporados pelos sujeitos envolvidos. ${ }^{14}$ De maneira geral, podemos integrar o território à política, ao cultural, e à economia que, de acordo com cada contexto, podem apresentar-se com mais ou menos intensidade no processo de formação territorial e de territorialidade.

O território é resultante do poder exercido por pessoas ou grupos, sem os quais o mesmo não se define..$^{15}$ Assim, devemos distinguir os territórios de acordo com aqueles que os constroem: os indivíduos, os grupos, o Estado, as empresas, ou seja, todos envolvidos. Em outras palavras, a criação de um território corresponde a uma dada territorialidade que visa a atingir, afetar, influenciar ou controlar pessoas, fenômenos e relacionamentos. ${ }^{16}$

Nesse sentido, as configurações diversas e plurais dos territórios, as dinâmicas sociopolíticas e a condução política são insumos para estudar os processos de conformação territorial. Porém, há uma dinâmica identitária que se produz em meio às disputas impostas pela identidade territorial, o que gera conflitos suscetíveis de serem orientados e regulados por cada um dos lados em confronto. ${ }^{17}$

Feitas essas observações conceituais, passemos, então, à apresentação dos primeiros movimentos, que vão desde o surgimento de Antônio Dias até a emancipação do território de Ipatinga. Tais movimentos contribuíram, enquanto realidades representativas, para configurar os aspectos políticos e geográficos, socioculturais e históricos que, lidos à luz dos Estudos Territoriais, revelam nuances significativas face à proposta deste artigo.

Nesse sentido, nos servimos de várias de fontes: memorialistas dedicados ao tema, cuja diversidade narrativa vai desde registros em forma de poemas - como é o caso do Sr. João Batista Guerra, em o Vazio Verde: o amanhecer de Ipatinga -, até as também valiosas contribuições dos jornalistas Carlindo Marques Pereira e Marcelo de Freitas, que estiveram entre os primeiros a narrar o episódio conhecido como o Massacre de Ipatinga. $\mathrm{Na}$ época do lançamento da primeira edição do seu livro 0 Massacre de Ipatinga, no início dos anos 1980, Carlindo era muito bem entrosado no meio político da cidade e um dos representantes dos movimentos de esquerda da "Chapa

\footnotetext{
${ }^{14}$ HAESBAERT, op. cit.; RAFFESTIN, op. cit.

${ }^{15}$ RAFFESTIN, op. cit.

${ }^{16}$ SACK, op. cit., p. 6.

${ }^{17}$ ZAMBRANO, Carlos Vladimir. Territórios plurales, cambio sociopolítico y gobernabilidad cultural. Boletim Goiano de Geografia - Instituto de Estudos Sócio-Ambientais/Geografia: Universidade Federal de Goiás (Edição Especial 20 anos), vol. 21, n. 1, jan./jul. 2001, p. 18.
} 
Ferramenta", paradoxalmente nascida dentro da Usiminas, pelo Partido dos Trabalhadores - PT. ${ }^{18}$

Já Marcelo de Freitas, graduado em comunicação e acadêmico em jornalismo, fez de sua obra uma boa articulação entre o mundo jornalístico e o acadêmico, apresentando-nos um texto que vai muito além de uma simples descrição dos fatos, observação que também pode ser apreciada na orelha do seu livro, registrada por Guy de Almeida.

Não podemos deixar de citar as produções acadêmicas, como a monografia de Roberta Milhôlo, com entrevistas ricas em conteúdo e cuidado científico. As dissertações das historiadoras Marilene Tuler e Ana Maria Carvalho Miranda Sá. A primeira, em uma perspectiva histórica, estudou o massacre dos operários de Ipatinga; a segunda retratou a formação cultural da região, em especial as festas de congado, desde o século XIX. Já Magnus Emmendoerfer, voltado para a Administração, nos beneficia com informações sobre os primórdios da estrutura, tanto física quanto administrativa, da Usiminas, entre os anos de 1962 e $1964 .^{19}$

Outra importante fonte de pesquisa foi a consulta à Revista Ipatinga: ano 20, uma produção repleta de registros sobre a história de Ipatinga, material encomendado pela Prefeitura na década de 1980, na gestão de Jamil Selim de Sales, político de direita e o primeiro prefeito eleito depois da emancipação, saindo-se vitorioso em outros dois pleitos futuros. Assim como essa revista, nos servimos dos fascículos editados pela Fundação João Pinheiro: Projeto Usiminas 25 anos, material encomendado pela Usiminas na década de 1980, que também se dedica a nos contar a história de Ipatinga segundo a visão dos engenheiros e convidados, pioneiros desde a idealização até a sua fase de produção. Entretanto, em nenhum desses trabalhos há uma preocupação em discutir de maneira mais consistente a formação do território estudado. Há apenas informações pontuais que buscamos agrupar para uma análise mais circunstanciada. ${ }^{20}$

${ }^{18}$ GUERRA, João Batista. Vazio Verde: o amanhecer de Ipatinga. sl.: Edição Editora Nova, sd. PEREIRA, Carlindo Marques. O Massacre de Ipatinga. 2. ed. 1984. FREITAS, Marcelo. Não foi por acaso: a história dos trabalhadores que construíram a Usiminas e morreram no Massacre de Ipatinga. Belo Horizonte: Comunicação de Fato, 2008.

${ }^{19}$ MILHÔLO, Roberta. O processo de emancipação de Coronel Fabriciano. 2007. 93 f. Monografia (Licenciatura em História) - Faculdade de História, Unileste, Coronel Fabriciano, MG, 2007. SÁ, Ana Maria Carvalho Miranda. Entre santos, coroas e fitas: a tradição por um fio. O congado em Ipatinga: século XIX até a atualidade. 2006. 119 f. Dissertação (Mestrado em História Social) - Programa de Mestrado em História Social, Universidade Severino Sombra, Vassouras, RJ, 2006. TULER, Marilene A. Ramalho. Massacre de Ipatinga Mitos e Verdades. Belo Horizonte: O Lutador, 2007. EMMENDOERFER, Magnus Luiz. Op. cit.

${ }^{20}$ PINTO, Luiz Carlos; ANDRADE, Alencar Linhares; OLIVERA, Wilton Rodrigues de. Ipatinga - Ano 20.Ipatinga: Diário do Aço, 1984. FUNDAÇÃO JOÃO PINHEIRO. A criação da Usiminas. In: Usiminas 25 anos. Belo Horizonte, 1986. (Depoimento de Lucas Lopes). 
Patrícia Falco Genovez; Vagner Bravos Valadares

\subsection{Do surgimento de Antônio Dias à emancipação de Coronel Fabriciano}

Sobre Antônio Dias, há registros de que a cidade foi um núcleo bandeirante cujo aparecimento data de 1706, período em que o sertanista Manuel de Borba Gato estivera em Minas Gerais e, ao voltar para São Paulo, estimulou o também sertanista Antônio Dias de Oliveira a organizar sua bandeira e partir em busca de ouro e de pedras preciosas. Antônio Dias prontamente seguiu as orientações recebidas e, na região de Itacolomi, fundou o povoado de Antônio Dias Acima, hoje um bairro da cidade de Ouro Preto. $O$ sertanista deslocou sua bandeira seguindo às margens do rio Piracicaba, e, ao encontrar um descampado em meio à mata, próximo à margem do rio, organizou um acampamento de base, no qual veio a surgir o povoado de Antônio Dias Abaixo, localidade hoje denominada Arraial Velho, primeiro marco da atual cidade de Antônio Dias. Nesse local foi construída a capela de Nossa Senhora do Rosário, que ainda existe. Porém, tempos depois, o povoado foi transferido para dois quilômetros abaixo, seguindo o curso do rio pela margem esquerda, onde hoje se encontra a sede do município. ${ }^{21}$

Antônio Dias foi elevado à condição de vila "de acordo com a Lei Estadual n 556, de 20/07/1911", ${ }^{22}$ com a denominação de Antônio Dias Abaixo e como território desmembrado do município de Itabira. Em virtude da Lei Estadual nº 716 de 16 de setembro de 1918, o município de Antônio Dias Abaixo passou a denominar-se Antônio Dias. Antes dessa lei, ainda como distrito, o local era denominado Vila de Antônio Dias Abaixo. O Município de Antônio Dias "possuía nesse período $845 \mathrm{~km}^{2}$ e localizava-se à margem esquerda do Rio Piracicaba, na Zona do Rio Doce. ${ }^{23}$

Em meio ao processo de territorialização, destaca-se a Serra dos Cocais, caracterizada por um rústico povoado denominado Santo Antônio que, em "1923 recebe a instalação de um cartório e, a partir desse momento, é elevado à categoria de distrito do município de Antônio Dias, com o nome de Santo Antônio do Piracicaba". ${ }^{24}$ No início de 1922, a região da Serra dos Cocais não passava de uma floresta virgem. Porém, quando chegaram os

${ }^{21}$ IBGE. Enciclopédia dos Municípios Brasileiros: Minas Gerais. Belo Horizonte: IBGE, 1959. Volume 24, p. 85.

${ }^{22}$ Lei Estadual n 556 de 20 jul. 1911. Dispõe sobre a divisão Administrativa do Estado e contém outras disposições. Disponível em: http://hera.almg.gov.br/cgi-bin/nph-brs Acessado em: 03 nov. 2009

${ }^{23}$ IBGE, op. cit., p. 85.

${ }^{24}$ Ibidem. 
primeiros engenheiros para a construção da Estrada de Ferro Vitória-Minas, a região começou a se desenvolver juntamente com sua vizinha Melo Viana. ${ }^{25}$

É nesse período que mais se destaca a figura de Fabriciano Felisberto de Carvalho Brito, conhecido como Coronel Fabriciano. Foi ele quem pleiteou a emancipação política da Vila de Antônio Dias. O Coronel era líder local e político influente na região, além de importante representante dos estabelecidos locais. Ao perceber que a extensão territorial da Vila não era suficiente e que seria necessário alargar suas fronteiras, o Coronel aproveitou-se da posição que seu filho, dr. Carvalho de Brito, ocupava no governo estadual (Deputado e membro da comissão responsável pela divisão administrativa de Minas Gerais), solicitando dele o desmembramento do povoado de Melo Viana em relação ao Município de Ferros, com sua imediata anexação ao de Antonio Dias ${ }^{26} \mathrm{Na}$ verdade, podemos indicar o uso de toda uma rede de poderes e estratégias que figuraram uma determinada territorialidade que almejava um reordenamento territorial.

Essa dinâmica territorial ganha intensidade em 1922, com o reinício dos trabalhos de construção da ferrovia, paralisada em Cachoeira Escura. Os engenheiros da Estrada de Ferro Vitória-Minas chegaram à localidade para o estudo de um plano de continuação das obras, cujo objetivo era atingir São José das Alagoas, onde seus trilhos seriam ligados aos da Estrada de Ferro Central do Brasil, ficando, assim, em comunicação direta com as capitais de Minas e do Espírito Santo. Desse modo, estabelecem-se redes e fluxos que passam a permear o território.

Em 1936, a Companhia Siderúrgica Belgo Mineira, com sede em Belo Horizonte e altos-fornos em João Monlevade, instalou, em Coronel Fabriciano, então distrito de Melo Viana, um escritório com o objetivo de explorar carvão vegetal, na zona do Vale do Rio Doce. À Belgo Mineira deve-se o impulso inicial da cidade: matas foram devastadas, dando lugar às ruas e construções de vários tipos. Houve, portanto, uma apropriação material do território.

Em agosto de 1938, o povoado de Melo Viana recebeu o nome de Coronel Fabriciano, em homenagem ao Tenente-Coronel Fabriciano Felisberto de Carvalho Brito, por ocasião de seu centenário de nascimento. Só em 1944, com a instalação da Companhia Aços Especiais Itabira (ACESITA), Coronel Fabriciano receberia o grande impulso que transformaria o distrito. Em

${ }^{25}$ BENEDITO JR., Fernando. As cidades da região nas primeiras décadas. In: Vale do Aço 2000. Ipatinga: Diário do Aço, 1999.

${ }^{26}$ MILHÔLO, op. cit. 
1940, o distrito já contava com 3.791 habitantes e, posteriormente, em 1948, o município foi criado, desmembrando-se de Antônio Dias. Consolidava-se, assim, um grupo de estabelecidos que emanava uma territorialidade capaz de dar novo formato ao território ao empoderar-se de uma rede com amplas ramificações políticas, econômicas e sociais, envolvendo lideranças locais.

o processo descrito remete ao plano de conformação política de um território legalmente estabelecido. Entretanto, retornando os aspectos conceituais expostos na primeira parte deste artigo, não se pode perder de vista que esse território político não é estático, mas permeado por relações de poder, e tem, no espaço, um componente indissociável, tanto na realização de funções quanto na produção de significados. Esse território pode ser funcional, a começar pelo seu papel enquanto recurso (recursos naturais/ matérias-primas) que variam em importância de acordo com os modelos de sociedades vigentes. ${ }^{27}$

Por isso a importância em apresentarmos o cenário, formado com a presença de grandes empresas e, também, os movimentos iniciais de territorialidade advindos com os grandes investimentos e transformações sociais, políticas e econômicas que chegaram a Coronel Fabriciano, e, nesse processo, os direcionamentos primários de novas redes que começavam a se estabelecer em função dos recursos acima descritos e recém-instalados no território.

Estamos diante da tessitura de novas redes e territorialidades, cujos registros dos movimentos iniciais se deram quando o dr. Rubem Siqueira Maia, um prestigiado médico da região, integrante do grupo de estabelecidos locais, em 1947, vendo-se diante de toda essa nova realidade, recorre ao seu velho amigo e então deputado estadual Tancredo Neves para pleitear a emancipação política de Coronel Fabriciano, com a justificativa de promover o desenvolvimento da região. Amigos desde a infância, ao se formarem (o dr. Rubem em Medicina e Tancredo Neves em Direito) o primeiro foi para Antônio Dias trabalhar como médico na Estrada de Ferro Vitória-Minas (E.F.V.M) e Tancredo Neves continuou na capital, onde dedicou o resto de sua vida à carreira política. Eles nunca perderam o contato, demonstrando as conexões entre as redes locais e a política do Estado de Minas. ${ }^{28}$

Estrategicamente, o dr. Rubem estrutura uma Comissão para levar adiante o ideal de emancipação e procura reunir homens que já tinham,

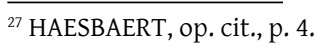

${ }^{28}$ MILHÔLO, Roberta. Op. cit., p.14. 
assim como ele, alguma projeção na sociedade. Portanto, eram indivíduos com prestígio social, ligados a setores de destaque, a ramos de atividades liberais, públicas, comerciais e empresariais, ou seja os estabelecidos.

Fizeram parte da Comissão:

1) Dr. Rubem Siqueira Maia - um dos primeiros médicos da região, veio para o distrito como funcionário da Cia. Belgo Mineira, em 1938. Foi comerciante e empreiteiro na construção da Cia Acesita. Mais tarde, adquiriu experiência política ao ser prefeito do Município de Antonio Dias, filiado, na ocasião, ao partido PSD;

2) Coronel Silvino Pereira - era um pioneiro no lugar. De origem sergipana, o Cel. prosperou economicamente ao trazer nordestinos para trabalhar na EFVM, ainda na década de 1920. Era comerciante e foi o primeiro proprietário de máquinas de beneficiamento de alimentos da região;

3) Lauro Pereira - era parente do Cel. Silvino e como tal aproveitou para ingressar no comércio. Posteriormente, com a instalação da Companhia Acesita, tornou-se empreiteiro de carvão dessa empresa;

4) Nicanor Ataíde - político de formação, era filiado a UDN, o mesmo partido do governador do Estado na época, dr. Milton Campos. Era comerciante e proprietário da Casa Ataíde;

5) Claudiano José Soares - era secretário da Cia. Belgo Mineira, e, portanto, sempre estivera bem próximo do dr. Rubem Siqueira Maia. Tinha uma gráfica e provavelmente deve ter feito parte do grupo responsável pela redação do jornal impresso 0 Progresso, que se tornou um dos mais importantes instrumentos de divulgação dos ideais emancipacionistas;

6) Narciso Tôrres - comerciante e gerente das Casas Guerra. Apesar da pouca idade - tinha apenas 25 anos -, entrara na comissão para agregar forças e participar das mudanças da comunidade;

7) José Anastácio Franco - era proprietário de uma casa de comércio e tinha sido Juiz de Paz por algumas vezes;

8) Joaquim Vieira Alves - natural de Mesquita, recém-chegado ao distrito, se dedicou ao comércio e a política;

9) Wenceslau Martins Araújo - funcionário da Cia. Acesita. Topógrafo por formação, foi provavelmente indicado pelo sr. Alderico Rodrigues de Paula, um dos diretores da Cia.;

10) padre Deolindo Coelho - vigário há muitos anos. Atendia toda a região e conhecia muito bem a população do lugarejo. Estava à frente dos trabalhos de construção da Paróquia São Sebastião, que consistia em uma obra grande e com previsão de inauguração para o ano $1948 .^{29}$

Nessa organização presidida pelo dr. Rubem Siqueira, registramos os primeiros indicadores do processo de territorialização que se instalava no

${ }^{29}$ MILHÔLO, op. cit., p.15. 
distrito de Coronel Fabriciano. Assim, com a força da rede que foi formada para sustentar essa territorialização - já que esse grupo havia sido constituído de seus respectivos poderes políticos e econômicos -, passou-se a recorrer aos órgãos competentes do Estado solicitando, ainda em 1947, a emancipação política e administrativa de Coronel Fabriciano, conectando as redes de poderes locais e estaduais.

Nesse sentido, é bom lembrar que todo território possui um caráter político, de onde derivam as distintas variantes do poder que estão presentes tanto de forma simbólica como funcional na constituição das instituições, empresas e relações sociais..$^{30}$ Assim, a configuração do agrupamento das representações sociais, formado pelas dez pessoas convidadas pelo dr. Rubem Siqueira, perfaz um emaranhado de poder por ele tecido que institui tal grupo como o dos estabelecidos.

Mesmo assim, a Lei Estadual n 28, de 1947, em seu artigo 05, previa os critérios necessários para a instalação de qualquer município mineiro: para a emancipação, deveria haver no mínimo 10 mil habitantes e Coronel Fabriciano, nesse momento, possuía apenas 5 mil. 0 governo de Minas não aprovou a instalação do município. O Senhor Narciso Drumond Tôrres narra, em entrevista, que diante dessa negativa o grupo do dr. Rubem adota a sugestão do deputado Tancredo Neves para que o padre Deolindo Coelho fosse envolvido e fornecesse os registros de batismo para que fossem acrescentados ao censo de habitantes, feito precariamente por Antônio Dias. Com esse procedimento, o número de habitantes excedia os 10 mil exigidos por lei. "Além do padre Deolindo Coelho, foi incluído na Comissão o sr. Wenceslau Martins Araújo, provavelmente (sic) indicado pelos diretores da Cia. Acesita. Ele era topógrafo e ficou responsável de elaborar a planta com a proposta de divisas territoriais para o novo município". ${ }^{31}$ Nesse sentido, pode-se indicar que muito provavelmente tanto o padre quanto o topógrafo não fizessem parte do grupo de estabelecidos locais, mas constituíam figuras importantes no processo de desmembramento, o que facilitou a aproximação e aceitação de ambos.

Essa soma de forças foi complementada por uma nova estratégia de luta que consistia em mobilizar a comunidade, agregando outros grupos ao processo. 0 dr. Rubem Siqueira teve a ideia de criar o jornal impresso 0 Progresso. 0 jornal se tornou um importante instrumento de veiculação das

${ }^{30}$ HAESBAERT, op. cit. e RAFFESTIN, op. cit.

${ }^{31}$ MILHÔLO, op. cit. 
ideias emancipacionistas, tendo como redator-chefe o dr. José Albeny, um influente médico do Hospital Siderúrgica, criado posteriormente em Ipatinga, em 1948.

Em uma outra entrevista, o senhor Aloisio Letro disse que diante de uma segunda negativa do Estado, a Companhia Acesita entrou no processo, reformulou a documentação, gerou um extenso memorial e o enviou novamente à Assembleia no dia 25 de fevereiro de 1948. Em 08 de outubro do mesmo ano, os deputados emitiram opinião favorável e, com uma grande contribuição do governador Milton Campos, no dia 27 de dezembro de 1948, em conformidade com a Lei 336/48, o distrito de Coronel Fabriciano, mediante a incorporação do arraial de Ipatinga, é emancipado. ${ }^{32}$ É estabelecido um novo território, e, a partir de agora, uma nova construção social e dinâmicas identitárias começam a tomar corpo dentro de um contexto histórico, já de antemão marcado pelas pessoas que não somente idealizaram a emancipação de Coronel Fabriciano, mas conduziram toda uma população aos seus ideais emancipacionistas, e, neste continuum, encontra-se o arraial de Ipatinga, que nesse contexto passa a pertencer a Coronel Fabriciano.

\subsection{Da vinda dos imigrantes ao surgimento do distrito de Ipatinga}

O nascimento do distrito de Ipatinga nos remete aos primeiros movimentos de formação política e social desse jovem território, acompanhados de uma intensa transformação social e de relações de poder. 0 arraial de Ipatinga era rota de tropas que cortavam a região sobrevivendo do comércio de arroz, feijão e toucinho que eram exportados dali. Havia também "uma dependência de importação de querosene, sal, sardinha, bacalhau e a Cerveja Antártica (sic), vindos de Cachoeiro do Itapemirim - ES, surgindo uma interligação por esses tropeiros do arraial, ao sul da Bahia e o interior de Minas Gerais e Rio de Janeiro".

Nessa parte do Rio Doce existiam inúmeras vilas e pequenas cidades que se formaram há muitos anos - mesmo alguns séculos, como é o caso de Marliéria, antigo forte expedicionário "Babilônia" comandado por Guido Marliére com o intuito de fazer frente aos índios Botocudos... como característica que as unia no passado está a distância de quase tudo que se conhece como bens de consumo ou que gerasse conforto.

É nesse universo que se localiza Barra Alegre e Ipatinga, um dos pontos de passagem entre as já constituídas cidades de Antônio Dias, Mesquita,

${ }^{32}$ Ibidem. 
Patrícia Falco Genovez; Vagner Bravos Valadares

Joanésia e Coronel Fabriciano. Eram cidades formadas há muitos anos como rota de tropeiros, ponto de parada de comitivas ou pequenas fazendas que se constituíram como cidadelas, algumas, mesmo antes da proclamação da república, ou seja, são cidades que surgiram dos povoamentos mais antigos desse trecho e não foram formadas pela relação direta com a Estrada de Ferro Vitória-Minas. ${ }^{33}$

Foi também por esse movimento que o arraial de Ipatinga passou a conviver com uma nova política de migração, com a chegada dos primeiros imigrantes europeus, árabes e, posteriormente, os asiáticos que vieram para iniciar uma nova vida, principalmente depois da construção da estrada de ferro, em $1924 .{ }^{34}$ Percebe-se, portanto, a existência de famílias que ocuparam inicialmente o arraial, produzindo para a subsistência da região. Um grupo pequeno de estabelecidos vinculados à terra em meio a grupos de outsiders em movimento contínuo que cortavam o território com tropas. Mais tarde, a política de imigração trouxe novos grupos que também, inicialmente, se configuraram como outsiders.

A busca por mão de obra nesse período contou com duas iniciativas: a primeira partia de uma proposta do Estado que procurava atrair colonos com o discurso de terras férteis, isenção fiscal e perdão de dívidas para com a Fazenda Real; a segunda correspondeu às tentativas de particulares na montagem de núcleos populacionais usando recursos do Estado. Os primeiros movimentos para atrair colonos para o Norte da Província de Minas ocorreram na metade do século XIX, quando Teófilo Otoni criou a Companhia do Mucuri, em $1853 .{ }^{35}$ Essa prática fora uma constante também por toda a Zona da Mata Mineira, no período Imperial. Para contrastar com a iniciativa de Teófilo Otoni para a parte norte da região, temos a iniciativa de Mariano Procópio Ferreira Lage para a parte sul. Mariano criou, na década de 1850, na cidade de Juiz de Fora, a Cia. União e Indústria, e em 1861, recebeu 1.152 colonos para ocuparem as vilas agrícolas de São Pedro, Borboleta e Fábrica. ${ }^{36}$

Esse processo de ocupação territorial ainda não se encontrava finalizado até a metade do século XX. No caso de Coronel Fabriciano, a população

\footnotetext{
${ }^{33}$ RIBEIRO FREITAS, Geraldo Vinícius. Entre divisas, divisores e um massacre: a emancipação da não construída cidade de Ipatinga-MG. 2011, Dissertação (Mestrado em História). Programa de Pós Graduação do Instituto em História, Universidade Federal de Uberlândia, Uberlândia, Minas Gerais, 2011.

${ }^{34}$ PINTO, Luiz Carlos; ANDRADE, Alencar Linhares; OLIVEIRA, Wilton Rodrigues de. Determinação, luta vitória. In: Ipatinga - Ano 20. Ipatinga: Diário do Aço, 1984, p.7-18.

${ }^{35}$ Ibidem. p. 17. Para saber mais sobre a vida de Teófilo Otoni ver: CHAGAS, Paulo Pinheiro, 1906. 3. ed. Teófilo Ottoni/Belo Horizonte: Ministro do Povo/Itatiaia, 1978.

${ }^{36}$ OLIVEIRA. Mônica R. de. Juiz de Fora: vivendo a história. Juiz de Fora: Ed. UFJF, 1994.
} 
esparsa permitia a exploração de grandes extensões de matas que passaram a interessar a Companhia Belgo Mineira. Com a intenção de explorar as matas para a fabricação de carvão vegetal para os altos-fornos de João Monlevade, a Companhia Belgo Mineira comprou as terras do sr. Alberto Giovanini, no Município de Coronel Fabriciano. Porém, em 1949, por meio de uma permuta com a Companhia Belgo Mineira, o terreno passa para a propriedade da Prefeitura de Coronel Fabriciano. Nos dias atuais, esse terreno se localiza exatamente onde hoje é o centro de Ipatinga. ${ }^{37}$

É nesse contexto que se registra a chegada das primeiras levas de imigrantes a Coronel Fabriciano e Ipatinga. A família Pidner foi uma das primeiras a chegar à região, oriunda do Tirol, na Áustria. Além de terem experiência no ramo comercial, atuavam também no ramo de estruturas metálicas e na manutenção de vagões para a Estrada de Ferro Vitória-Minas. Os Pidner ajudaram a construir os teleféricos da Cia. Belgo Mineira em João Monlevade, na década de 1950. Na década de 1980, outras famílias europeias chegaram a Ipatinga, como os poloneses Duda e Czoksky, além de italianos e portugueses. É importante citar que, além dos europeus, os árabes tiveram participação decisiva no desenvolvimento comercial da região desde as primeiras décadas do século XX. Eles dedicavam-se ao comércio, mascateando de cidade em cidade ou se estabelecendo como prósperos comerciantes. Citamos como exemplo os Selim e os Tufik que deixaram o Líbano, fincando raízes em Ipatinga, onde a comunidade de descendentes árabes encontra referência ainda nos Chaim, Saraf e várias outras famílias. ${ }^{38}$

Esses imigrantes nos indicam o surgimento de um grupo que almejava se tornar estabelecido comandando o comércio da região. Eles configuraram uma territorialidade específica, tendo em vista que anteciparam uma vocação que viria a marcar profundamente a futura cidade de Ipatinga, ou seja, a presença dos estrangeiros em seus domínios com o propósito de comprar ou vender, atraídos pelo perfil multinacional da Usiminas.

A abertura dos trabalhos da Belgo Mineira e da Acesita na exploração do carvão, no ano de 1934, trouxe um grande número de operários. Alojados à margem do Ribeirão Ipanema, formaram um grande povoado no lugarejo, motivo para a Companhia Estrada de Ferro Vitória-Minas mudar-se para o local, já que tinha sua estação às margens do Rio Piracicaba. ${ }^{39}$ Novamente,

${ }^{37}$ PINTO, Luiz Carlos; ANDRADE, Alencar Linhares; OLIVEIRA, Wilton Rodrigues de. A chegada Belgo. In: Ipatinga - Ano 20. Ipatinga: Diário do Aço, 1984, p. 2.

${ }^{38}$ BENEDITO JR. Op. cit., p.19

${ }^{39}$ DIÁRIO DO AÇO ${ }_{(b)}$. Vale do Aço 2000: Um século de História. Ipatinga: Diário do Aço, 1999. pp. 10, 11-13. PINTO; ANDRADE; OLIVEIRA, op. cit., p. 2. 
podemos indicar a formação de um grupo de outsiders que compunha com outros, de mesmo status, um cenário complexo em um território em transformação.

Com as maciças atividades de carvoaria, as áreas até então cobertas por florestas no arraial de Ipatinga se transformaram em fazendas, como a Fazenda Ipanema, onde hoje é o atual Bairro Veneza I. Maria Weber de Oliveira, conhecida como dona Bizuca, filha de Pedro Soares de Oliveira e Ana Anício de Oliveira, nascida em Santana do Paraíso, Mesquita, Minas Gerais, em 21 de dezembro de 1932, foi professora em Ipatinga, herdando as funções de Dona Maria Antonieta, então primeira docente da região. Ela lecionou nas Escolas Reunidas Júlia Kubitschek (1957 a 1961), onde foi também diretora de 1961 a 1964, depois, assumiu a diretoria da Escola Manoel Ezídio, de 1964 a 1986, tendo participado dos primeiros movimentos de emancipação de Ipatinga. Dona Bizuca conta que o local era apenas uma parada de trem. "Depois, passou a ser depósito de material da Companhia Alâmbra para a construção da Usina hidroelétrica de Salto Grande. No princípio, existiam os derrubadores de matas, depois veio a fabricação de carvão e o restante da madeira era despachado pela estrada de ferro". ${ }^{40} \mathrm{O}$ local era repleto de tropeiros e fazendeiros (outsiders e estabelecidos), dentre os quais se destacava Jair Gonçalves. Sua fazenda era onde se situa o Bairro Cidade Nobre. A fazenda do pai de dona Bizuca começava no bairro Bethânia e se estendia pelos Bairros Canaã, Vila Militar, Canaãzinho e Vagalume. A propriedade foi vendida para Salim José de Sales, após a morte de sua mãe.

No início dos anos 1960, a situação da população era precária, "tudo que se tinha de resolver, questão de saúde, compras, só em Coronel Fabriciano. Não havia asfalto, passava-se com muita dificuldade, iase de trem para a sede da cidade porque era o meio mais seguro de se viajar" ${ }^{41}$ À medida que as dificuldades aumentavam, o domínio de Coronel Fabriciano sobre Ipatinga trazia mais insatisfação. Em outras palavras, "à medida que o lugar ia crescendo, já se falava em trazer a indústria e outros melhoramentos. Então, politicamente, Coronel Fabriciano exercia o paternalismo sobre nós. Não tínhamos posto de saúde e até para assistir missa em Ipatinga era difícil". ${ }^{42}$

${ }^{40}$ RUEDA, Lenira \& NAHAS Júnior, Antônio (coord.). Homens em série: A história de Ipatinga contada por seus próprios personagens. v.1. Ipatinga: Prefeitura Municipal de Ipatinga, 1991.

${ }^{41}$ Ibidem.

${ }^{42}$ Ibidem. 
Na mesma linha do depoimento de dona Bizuca, o senhor Raimundo Anício $^{43}$ declara que, devido aos escassos recursos direcionados a essa região por parte da Prefeitura de Coronel Fabriciano, o povoado encontrava-se sem nenhum conforto. No tempo de chuva, muito barro; no tempo de sol, muita poeira. Até 1958 , a cidade configurava-se como uma pequena vila, com cerca de 300 habitantes e 60 casas. Ele destaca que mesmo com toda a precariedade de urbanização local, o comércio sofria a influência do pessoal que fazia o transporte de um complexo de maquinário para a instalação da Usina Hidroelétrica de Salto Grande, município de Braúnas em Minas Gerais. "Tudo era descarregado em Ipatinga. E tinha uma presença muito grande do pessoal carvoeiro da Companhia Belgo Mineira, e esse pessoal fazia compra sempre aqui". ${ }^{44}$

A partir dos elementos levantados, é possível propor um cenário: de um lado, temos a sede plenamente estabelecida em suas relações de poder em comparativamente ao arraial de Ipatinga; do outro, um jovem território em formação, imerso em um processo caracterizado por baixa densidade demográfica, formado essencialmente pelo estabelecimento de fazendeiros (considerados estabelecidos locais), migrantes (outsiders em processo de estabelecimento) de diferentes pontos do Estado, do país e do mundo, formando um contingente populacional de pessoas com raízes completamente diversificadas.

De certo, temos que o arraial de Ipatinga pertencia, na perspectiva jurisdicional, a Coronel Fabriciano. Do ponto de vista de arrecadação de impostos, não apresentava razões significativas que atraíssem, nessa fase inicial, a atenção de sua sede. Porém, como anteriormente já registramos, esse arraial passa a pertencer a Coronel Fabriciano por causa de uma manobra política para a sua emancipação de Antonio Dias. Podemos nos perguntar se o fato desse objetivo ter sido alcançado, somado à baixa representatividade do arraial de Ipatinga aos cofres públicos, não teria projetado um território com características marcadamente desvalorizadas pelos grupos dirigentes da sede. Pautados nessa projeção territorial, o poder público de Coronel

\footnotetext{
${ }^{43}$ Raimundo Anício foi juiz de paz em Antônio Dias, entre 1948 e 1952. Empreiteiro da Belgo Mineira, fazendo carvão, estabeleceu-se no arraial de Ipatinga em 1953; era o único fornecedor de eletricidade para os moradores e trabalhava para Magalhães Pinto eleger-se deputado, participava da UDN. Em 1960, ele foi vereador representando o distrito. Estruturou uma boa rede de relacionamento com as pessoas que faziam a direção da Usiminas. Nunca teve problemas com a usina e sempre teve seus pedidos atendidos pela empresa.

${ }^{44}$ FUNDAÇÃO JOÃO PINHEIRO. A Comunidade. Usiminas 25 anos. Belo Horizonte, 1987, p.7-10. (Depoimento de Raimundo Anício Alves).
} 
Fabriciano manteve o mesmo padrão de administração, desconsiderando o rápido crescimento demográfico e o desenvolvimento socioeconômico em curso. Da mesma forma, as redes de poder já constituídas em Coronel Fabriciano não parecem ter feito qualquer movimento no sentido de agregar novos personagens que já se destacavam no então distrito de Ipatinga.

Como pudemos perceber, o arraial de Ipatinga já possuía alguns grandes fazendeiros formalmente instalados, estabelecidos. A região se tornara um entreposto de tropeiros (outsiders em trânsito), onde todos os maquinários para a construção da Usina Hidroelétrica de Salto Grande eram descarregados. Havia o movimento das carvoarias da Belgo Mineira e da Acesita, que constituíam territorialidades externas àquele território já permeado por suas próprias territorialidades. A Vale do Rio Doce não somente alterou o traçado da estrada de ferro, como trouxe a estação ferroviária para o meio do povoado. Naquele momento, já se cogitava sobre as obras da construção da Usiminas. É possível ver, assim, várias territorialidades e redes em formação em meio a uma complexa ordem de ações planejadas ou não pelos grupos sociais ali residentes. Ou seja, havia a formação de nova ordem originada da combinação de várias ações isoladas, cujas configurações sociais estavam levando aquelas pessoas à regularidade e à assimilação de um certo discurso como os de d. Bizuca e do sr. Raimundo Anísio, unindo-os a um processo de territorialização que culminou na emancipação de Ipatinga. Todo esse processo é permeado pela multidimensionalidade de seus membros, que começavam a perceber-se em uma coletividade, conectados em redes, em um sistema de relações existenciais e produtivas. ${ }^{45}$

Com base nesses pressupostos, no início de 1953 vemos que no arraial de Ipatinga se articula um dos primeiros movimentos de expressiva organização social, quando Raimundo Anício Alves, José Anatólio Barbosa, Jair Gonçalves e Raimundo Nonato Vieira organizam uma comissão para criar o distrito de Ipatinga ${ }^{46}$ No mesmo ano, Ipatinga vira distrito, instalado sob a presidência do juiz de direito da Comarca de Antônio Dias dr. José Grossi. Ele fixa a data para instalação do distrito (criado pela Lei no 1.039) em 12 de dezembro de 1953, pois no período de $1^{\circ}$ de janeiro de 1954 a 31 de dezembro de 1958 seria estabelecida a divisão administrativa e judiciária do Estado. O distrito de Ipatinga passa a apresentar, assim, os seguintes dados físicos: está localizado na Microrregião do leste de Minas Gerais, abrangendo parte

${ }^{45}$ RAFFESTIN, op. cit.

${ }^{46}$ BENEDITO JR., Fernando. A cidade de Ipatinga. In: Ipatinga: a cidade em pauta. Ipatinga: Câmara Municipal de Ipatinga, 2005. p.18. 
da bacia do Rio Doce (Piracicaba e Ribeirão Ipanema), tendo uma altitude de $220 \mathrm{~m}$ e $160 \mathrm{~km}^{2}$ de superfície. ${ }^{47}$

Torna-se perceptível o desenvolvimento de sistemas que se conectam, produzindo territórios-redes e enquadrando agentes com os mesmos propósitos territorializadores, cujo fluxo de interesses não necessariamente acontecia em um sentido vertical, mas cada vez mais horizontal por possuir uma maior representatividade social em um continuum entre estabelecidos e outsiders. E por suas definições de multiterritorialiade, Haesbaert nos faz refletir sobre três aspectos que mantêm estreita relação com a dinâmica territorial das corporações. O primeiro deles é o processo de "reterritorialização", ou seja, território é movimento, o segundo aspecto é a "possibilidade de acesso ou de conectar-se", e o último aspecto a destacar é que a multiterritorialidade implica "redes não-hierárquicas". ${ }^{48}$

Voltando ao depoimento do sr. Raimundo Anício, supracitado, há uma declaração dele no sentido de que, passada quase toda a década de 1950, Ipatinga, já com o status de distrito, apresentava-se ainda sem qualquer infraestrutura. As ruas eram de terra, a luz a motor e a água fornecida em lombo de burro ou carros-pipa.

Como já mencionado anteriormente, uma possível causa para tanto abandono por parte da Sede em relação ao arraial de Ipatinga pode ter ocorrido pela forma como se deu sua anexação e pela sua baixa representação aos cofres públicos. Entretanto, um dado novo aparece. $\mathrm{O}$ distrito de Ipatinga passa a figurar na lista dos possíveis lugares para receber a Usiminas. Sobre o local da montagem da usina, os primeiros indicadores apontavam para Paraopeba, Governador Valadares, Itabira e Ipatinga, onde esta viria a ser realmente instalada. Em 1960, o pequeno e preterido distrito já convivia com um inimaginado movimento migratório.

O primeiro emissário da Usiminas para a região foi José Joaquim de Morais. Ao chegar a Ipatinga, seu contato foi com Raimundo Anício, a quem Morais, como ficou conhecido, explicou que precisava adquirir três casas pré-fabricadas desmontáveis, das que eram utilizadas nas obras de construção da Usina de Salto Grande. Nelas seriam instalados os topógrafos que fariam os primeiros levantamentos para a definição do local da futura usina. ${ }^{49}$

Raimundo Anício sabia onde encontrá-las e uma delas foi comprada

${ }^{47}$ IBGE, op. cit. p. 86.

${ }^{48}$ HAESBAERT, Rogério. Da desterritorialização à multiterritorialidade. Anais do X Encontro de Geógrafos da América Latina. São Paulo, Universidade de São Paulo, 2005.

${ }^{49}$ FREITAS, op. cit., p.174. 
do sr. Olinto Silva, dono do Cine São José. As outras duas foram adquiridas do sr. André Sales, que era agente da estação ferroviária. Percebemos aí o nascimento de uma fortíssima e poderosa rede. Se de um lado temos um representante dos mais altos escalões político e econômico do país, do outro temos um cidadão com respeitável credencial social, já que naquele momento ele já havia exercido (entre os anos de 1948 e 1952) a função de juiz de paz em Antônio Dias. Foi também empreiteiro da Belgo Mineira, proprietário do único armazém do distrito, teve especial participação na comissão para a criação do distrito de Ipatinga e foi o fundador da União Democrática Nacional - UDN, da região, configurando-se em um alto representante do grupo dos estabelecidos.

Em linhas gerais, o projeto mineiro previa a construção da grande siderurgia brasileira no Vale do Rio Doce, região com altíssima concentração de minério de ferro, utilizando carvão vegetal e energia elétrica complementar para a alimentação dos altos-fornos. Além disso, pressupunha que, ao Estado, deveriam caber os investimentos e, principalmente, a propriedade da empresa. A partir da definição dos pontos de estrangulamento regionais e dos pontos de germinação futuros, a gestão JK em Minas voltou-se para a industrialização, diminuindo gradativamente a importância do setor agrário como ponto de investimento do Estado..$^{50}$

Mas, a partir de 1955, com a Implantação do Plano de Desenvolvimento Industrial de Juscelino Kubitschek, Amaro Lanari articula um movimento para a implantação da primeira grande Indústria Siderúrgica em Minas Gerais. Paralelamente a esse movimento pró-siderurgia brasileira, o governo japonês e seu empresariado demonstraram interesse na exportação de tecnologia siderúrgica para o Brasil, para mostrar competitividade em um mercado no qual não tinha tradição, diante de países como Inglaterra, Estados Unidos e França. ${ }^{51}$

No dia 25 de abril de 1956, com Escritura Pública lavrada na sede da Federação das Indústrias de Minas Gerais - FIEMG, fundava-se a Usiminas, e durante 18 meses foram estabelecidas as condições necessárias para que fossem efetivados os contatos com os sócios japoneses e o apoio do governo brasileiro, tendo como representantes principais o sr. Amaro Lanari Junior e

${ }^{50}$ BARBOSA, Lidiany Silva; BARBOSA, Daniel Henrique Diniz. Engenheiros Mineiros na era Vargas: uma contribuição sobre a atuação do corpo técnico, as políticas públicas e o processo de desenvolvimento regional de Minas Gerais. Disponível em: http://www.cedeplar.ufmg.br/seminarios/seminario_diamantina/2006/ D06A069.pdf Acessado em: 02 dez. 2010.

${ }^{51}$ EMMENDOERFER, op. cit., p. 81-92. 
o sr. Teizo Horikoshi. Assim, nasce a Usiminas como a primeira joint venture feita pela indústria japonesa no ocidente, após a Segunda Guerra Mundial, cujo aporte de capitais ficou assim distribuído: $20 \%$ do Governo de Minas Gerais, $40 \%$ do Governo Federal e $40 \%$ do Japão. ${ }^{52}$

Deu-se por concretizada, então, a história da luta pela Usiminas, em uma sequência de ações pela implantação de uma grande usina siderúrgica em Minas Gerais. No governo JK, todo o processo foi facilitado. Os mineiros dão início, na visão de Jayme de Andrade Peconick, a um movimento cívico, nacionalista e técnico ao mesmo tempo, em uma articulação que ninguém poderia segurar, muito menos um presidente mineiro. ${ }^{53}$

O nascimento da Usiminas foi um projeto audacioso não somente pela complexidade, mas também pela sua importância, já que foi concebida como o maior parque siderúrgico do Brasil e da América Latina, nos reservando uma trilha cheia de múltiplos territórios e de territorialidades, cujos poderes manifestados podem ser apreciados tanto na sua forma mais explícita, de dominação, quanto na forma implícita ou simbólica.

A partir de todas as informações acima, vislumbra-se para os siderurgistas envolvidos um cenário totalmente favorável, pois agora estavam amparados pelo Governo Federal. Coronel Fabriciano - que já possuía a Estrada de Ferro Vitória-Minas, além da Usina Hidroelétrica de Salto Grande a uma distância de apenas $50 \mathrm{~km}$ da região e uma área plana, com água à vontade do Rio Piracicaba, quase na junção do Rio Piracicaba com o Rio Doce - era uma situação ideal. Tinha também um solo com 35 metros de profundidade de areia compacta, o que favorecia uma fundação formidável e de fácil execução.

Assim, em 1950, foram firmados os primeiros acordos para a fundação da Usiminas. Começaram a chegar ao distrito de Ipatinga os representantes dos sócios japoneses, fato que justificou a presença do embaixador do Japão na região em 16 de agosto de 1958, quando foi cravada a estaca que seria o marco fundamental da construção da Usiminas. Depois, vieram os técnicos e engenheiros que trabalhariam na instalação dos equipamentos da Usina. Os japoneses foram os responsáveis pela tecnologia e pelo fornecimento dos equipamentos mais complexos da siderúrgica, marcando uma nova rota para o futuro do local.

\footnotetext{
${ }^{52}$ Ibidem.

${ }^{53}$ FUNDAÇÃo JOÃO PINHEIRO. In: Usiminas 25 anos. Belo Horizonte, 1987, p. 8-15. (Depoimento de Jayme de Andrade Peconick).
} 
Patrícia Falco Genovez; Vagner Bravos Valadares

\section{Considerações finais}

A anexação do arraial de Ipatinga por Coronel Fabriciano implicou em um reordenamento entre os grupos de estabelecidos e outsiders de ambas as localidades. Dada a posição pouco vantajosa do então distrito de Ipatinga em relação à nova sede, é de se pensar que até mesmo aqueles que possuíam um status de estabelecidos no antigo arraial tenham sido desconsiderados e relegados ao tratamento de outsiders em relação aos grupos da sede. De estabelecidos, no município de Antônio Dias, passam, por um lado, a agregados de uma sede que não os legitima enquanto tais. Por outro lado, pouco tempo depois da anexação assistem a um gigantesco processo de instalação do complexo industrial, sustentado por uma ampla rede de poderes ainda desconhecida para todos na localidade.

A questão central desse processo é que a anexação não representa apenas um ato político e legal, mas implica em um redimensionamento mais profundo no caso do arraial e depois distrito de Ipatinga, legitimado pelo decreto de transferência da nova ordem estabelecida, que, na realidade, transfere os que foram deslocados de seu status para uma outra condição, em que tanto o cenário quanto o horizonte de expectativas se alteraram drasticamente. 0 processo se dá de forma rápida, o que dificulta o contato e a interação com as redes já estabelecidas na sede. É importante considerar também que, naquela época, a distância até Coronel Fabriciano era longa e o acesso difícil, normalmente feito por trem. Mesmo após a transferência do território, a distância continua, assim como o estranhamento entre os grupos estabelecidos da sede e os estabelecidos do antigo arraial. Os registros falam de uma manobra política, o que nos permite levantar alguns questionamentos, mas sem uma resposta contundente. Entretanto, cabe ponderar se o processo teria ocorrido à revelia do grupo de estabelecidos do arraial que passara a distrito com a anexação, ou se a elevação de arraial a distrito, no momento da anexação, se configura em uma negociação, trazendo uma perspectiva mais positiva para o grupo de notáveis local.

É possível considerarmos, portanto, que a ausência de uma territorialidade mais ativa frente à antiga sede (o arraial de Ipatinga pertencia a Antônio Dias até 1953) configurou uma identidade que pode ter sido remodelada no momento da anexação à nova sede, Coronel Fabriciano. $O$ processo pode ter aberto a possibilidade de uma renovação e/ou redimensionamento dos grupos tanto de estabelecidos quanto de outsiders. Entretanto, na mentalidade dos vários grupos e, em especial, dos estabelecidos de Coronel Fabriciano, esse redimensionamento pode não ter sido percebido. 
A nova sede manteve a mesma postura que fora adotada pela anterior. Além disso, a anexação facilita um domínio absoluto do território, que acaba sendo a projeção de um espaço "útil" para a realização de ações que eventualmente pudessem gerar desconforto ou um redimensionamento na nova sede e que colocasse em risco os estabelecidos de Coronel Fabriciano. Por esse ponto de vista, o distrito de Ipatinga apresentava condições bem favoráveis para instalação da Usina pelos motivos técnicos (material/natural), mas era também um território que, na perspectiva de Coronel Fabriciano, não dispunha de territorialidades constituídas, capazes de integrar as redes de poderes já estabelecidas, forçando um equilíbrio de forças. Aliás, esse equilíbrio não tarda a ser pretendido pelos grupos no novo cenário que desponta com a possibilidade de instalação da Usiminas. Dessa forma, pessoas como os senhores Raimundo Anício Alves, Jair Gonçalves, Walter de Lima Sales, João Lamego Neto, José Carvalho e José Orozimbo da Silva, considerados cidadãos respeitados, estabelecidos e com suas respectivas representações no contexto social do distrito de Ipatinga, assumirão o controle do Processo de Emancipação do Distrito por meio da Associação dos Amigos de Ipatinga.

Em síntese, Ipatinga era o território com características favoráveis, tanto na sua dimensão material quanto imaterial para vivenciar o processo avassalador e transformador de instalação da Usiminas, distante o suficiente para manter seguro o território da sede, que apenas usufruiria dos "bônus" do empreendimento.

Estamos, sem dúvida, diante de um processo avassalador de anexações em sequência que levaram a um redimensionamento das forças políticas e sociais, reordenando o cenário da sociedade localizada na Serra dos Cocais. Assim, Antônio Dias tornou-se distrito de Itabira em 1918, anexou os distritos de Melo Viana (futura Coronel Fabriciano) e Hematita (futura Timóteo) em 1923, quando emancipou-se. Melo Viana passa a chamar-se Coronel Fabriciano em 1938 e, 10 anos mais tarde, anexa Timóteo na tentativa de desmembrar-se como município sem obter êxito, já que não possuía o número de habitantes exigido por lei. Logo em seguida, em 1953, Coronel Fabriciano anexa o arraial de Ipatinga para completar o número de habitantes necessário e se desmembra de Antônio Dias. O reordenamento jurídico dos municípios e a cascata de desmembramentos e de anexações revelam um movimento de mudança nas territorialidades estabelecidas concomitantemente a um redesenho dos territórios. Todo esse processo implica um contexto de incertezas e redefinições. Os grupos da elite, já considerados estabelecidos, se veem em uma situação de outsiders ao se submeterem a outros grupos 
de poder, cujas redes já se encontram empoderadas no e pelo território. No caso de Ipatinga, esse cenário ainda apresenta um diferencial significativo: a instalação da Usiminas, que representa não só um novo ator no cenário, mas também uma nova territorialidade que, em função de uma rede de poderes mais ampla, abrange a política do Estado de Minas e está conectada aos interesses do governo de JK, lança mão inclusive das prerrogativas do desenvolvimento e, assim, chega como mais um grupo de estabelecidos na região, realimentando a ciranda contínua entre estabelecidos e outsiders.

Artigo recebido para publicação em: 06/07/2013

Artigo aprovado para publicação em: 09/10/2013 